\title{
Characterization and Anticancer Effects of Folate Targeted Inotodiol Liposome From Inonotus Obliquus (Chaga Mushroom)
}

Yangpeng Lu

Tianjin University

\section{Xudong Gao}

Tianjin University

Zhongqin Chen

Tianjin University

\section{Zihan Xue}

Tianjin University

\section{Yanan Jia}

Tianjin University

Nannan Li

Tianjin University

\section{Yajie Wang}

Tianjin University

Haixia Chen ( $\nabla$ chenhx@tju.edu.cn )

Tianjin University https://orcid.org/0000-0002-2596-9622

\section{Research Article}

Keywords: triterpenoids, inotodiol, liposomes, characterization, anticancer activity, targeted therapy

Posted Date: February 26th, 2021

DOI: https://doi.org/10.21203/rs.3.rs-242884/v1

License: (1) This work is licensed under a Creative Commons Attribution 4.0 International License. Read Full License 


\section{Abstract}

Inotodiol, one tetracyclic triterpenoid isolated from inonotus obliquus (Chaga mushroom) possess excellent anticancer, antioxidant and anti-inflammatory activities, however it has not been applied to medical use due to its low solubility and low bioavailability. Liposome as a good nanodrug carrier with EPR and good biocompatibility has received much research attention. To improve the solubility and bioavailability of IOP, we prepared inotodiol liposomes (IOP-Lps) and folic-acid targeting IOP liposome (FA-IOP-Lps) by ultrasonic method, and their particle size, morphology, zeta potential, entrapment efficiency (EE) and drug loading rate (DL) were characterized by DLS, TEM, FT-IR and HPLC respectively. Their in vitro cytotoxicity of human cervical cancer cells HeLa, human liver cancer cells HepG2 and human breast cancer cells MCF-7 were assessed using the MTT assay. The results showed that IOP-Lps and FA-IOP-Lps possess significant anticancer effects. The results of TEM, FT-IR and DLS confirmed the formation of liposome. The particle size of IOP-Lps were $201.07 \pm 6.47 \mathrm{~nm}$ and $\zeta$-potential of $-50.2 \pm 0.5$ $\mathrm{mV}$, FA-IOP-Lps $224.33 \pm 1.86 \mathrm{~nm}$ and $\zeta$-potential of $-51.2 \pm 0.3 \mathrm{mV}$, the EE of IOP-Lps and FA-IOP-Lps were $79.14 \%$ and $77.33 \%$, respectively. IOP-Lps and FA-IOP-Lps could selectively kill HeLa, HepG2 and MCF-7 cancer cells while nontoxic to normal L02 cells. This is the first study to give out in vitro information of inotodiol's anticancer effects based on nanocarriers. Besides, this drug delivery system is of good sustained release and targeted delivery effects to promote the utilization of both inotodiol and other natural hydrophobic compounds in target treatment of cancers.

\section{Introduction}

According to National Institutes of Health $(\mathrm{NIH})$ and National Cancer Institute, cancer is of malignant tumor, a disease which abnormal cell grow with potential to invade or spread other parts of the body. WHO' s statistic shows that cancer is responsible for an estimated 9.6 million deaths in 2018 and is the second main cause of death in global among which the most common cancers are: breast cancers (2.09 million cases), lung cancers (2.09 million cases), colorectal cancers (1.80 million cases), prostate cancers (1.28 million cases), skin cancer (non-melanoma) (1.04 million cases) and stomach cancers (1.03 million cases), that is approximately 1 in 6 deaths is caused by cancer. About 18 million new cases occured in 2019 and the death number caused by it was about 8.8 million, took up $15.7 \%$ of all deaths[1]. Depending on the the patient's health condition and types, locations and grades of cancer, there are different treatment options that includes surgery[2], radiation therapy, chemotherapy, targeted therapy, laser therapy, hormonal therapy, immunotherapy and palliative care[3].

While patients may suffer greater pain in surgery and radiation therapy, they tend to chemotherapy, and it is the primary one among these treatment for over 20 types of cancers. The traditional way of delivering anti-tumor agents is through intravenous administration[4]. This administration leads to low drug concentrations in the diseased area, which leads to poor treatment results and longer treatment cycles. The low water solubility and bioavailability of these agents often require increased drug doses to achieve the desired therapeutic concentration in the target area, hence, varying degrees of side effects, such as 
damaging liver cells, causing systemic reactions, and inhibiting the bone marrow hematopoietic system[5], which limits the application of chemotherapeutics to a certain extent.

Targeted therapy, a new form of chemotherapy which targets specific molecular differences between normal cells and cancer cells. Targeted drugs often work by preventing cancer cells from replicating themselves as they can help prevent cancer cells' dividing and new forming. The first targeted therapy blocked the estrogen receptor molecule, inhibited breast cancer's growth. Another common example is the class of Bcr-Abl inhibitors, which are used to treat chronic myelogenous leukemia (CML) [6].

To date, targeted therapies are being effectively used for many common cancer types, including liver cancer, breast cancer, lung cancer, bladder cancer, kidney cancer, colorectal cancer, lymphoma, leukemia, pancreatic cancer, skin cancer, prostate cancer, and thyroid cancer as well as other cancer types[7].

Inotodiol, a natural triterpene isolated from Inonotus obliquus, is reported to posses excellent anti inflammatory[8], antioxidant activities and anticancer effects on common cancers including lung cancer, cervical cancer, stomach cancer, liver cancer, breast cancer and prostate cancer $[9,10]$, while doing very little damage to normal healthy liver cells. As inotodiol is a hydrophobic compound, despite that more than five derivatives[11,12] were synthesized to solve the low solubility, its low bioavailability and the lack of targeting still limit its use. To date, there is no report for inotodiol's anticancer research based on nanocarriers.

Liposomes, a spherical vesicle of less than $200 \mathrm{~nm}$ diameter have at least one lipid bilayer, is a novel drug carrier with good characteristics of biocompatibility, biodegradability and low toxicity, can be used to encapsulate hydrophobic and hydrophilic drug and release the encapsulated drugs continuously[13,14]. Owing to the enhanced permeability and retention effect (EPR), liposome are passive targeting, some ligands can be anchored on the surface of liposomes to realize specific tumor targeting[15-17].

Anticancer drugs that are delivered by tumor targeting vectors form a targeted drug delivery system that can focus the drug at the tumor site and selectively kill tumor cells. This method of administration avoids damage to normal cells and has been extensively studied[18].

Meada and Matsumura first proposed an enhanced permeability and retention effect (EPR) in 1986. Their study found the phenomenon in which macromolecules (molecular weights greater than $4 \mathrm{kDa}$ ) or nanoparticles $(10-800 \mathrm{~nm})$ could pass smoothly through the wall space of the tumor vessel due to the good vascular permeability of the tumor tissue[19,16]. Due to the lack of lymphatic reflux of the tumor, the macromolecules or nanoparticles entering the tumor cannot be metabolized, which leads to the accumulation of particles in the tumor. Compared to conventional low-molecular chemotherapeutic agents, large-molecular active substances and nano-active substances are retained in tumors, which enables passive targeting[20,21].

In contrast to passive targeting, active targeting is achieved through the interaction of specific ligands on drug delivery systems with receptors on their tumor cells[22,23]. 
Folic acid (pteroyl-L-glutamic acid) belongs to the vitamin B family and is widespread in green leafy vegetables, it plays an important role as a cofactor in single-carbon metabolizing cells, and is a vitamin necessary for the synthesis of DNA and RNA precursors and cell growth and development[24]. However, folic acid cannot be synthesized by mammalian cells. Reductions in folate carrier and membrane folate receptors both mediate cellular uptake of folic acid. Folate receptor exposure is usually less in adult tissues, but high levels of expression are found in only a few tissues, such as placenta, kidneys, lungs, and choroid complexes. Folic acid receptors are also highly expressed in cancers of epithelial origin, including cervical cancer, ovarian cancer, renal cell carcinoma, breast cancer, colorectal cancer, and choroid plexus[25]. Therefore, the selective overexpression of folate receptors in colon tumors and their high affinity for folic acid provide a unique opportunity for folic acid to be used as a targeting ligand to deliver anticancer drugs to tumor cells. The delivery of these folate-anchored liposome drugs has several advantages over direct binding to chlorophyll. Studies have shown that free folate and folate conjugates can be mediated by folate receptor-mediated endocytosis entry into cells[26,27]. Overexpression of folate receptors is found on the surface of most malignant diseases, but rarely on the surface of normal cells[28,29]. FA has a small molecular weight, simple chemical properties and no advantageous properties of immunogenicity, which makes it suitable for tumor-related therapy. An FA-modified carrier loaded with cancer drugs can bind to a folate receptor that is highly expressed on the surface of cancer cells, thereby increasing drug concentration at the tumor site and reducing toxic side effects on normal cells. This makes FA a good ligand candidate in the field of cancer biotherapy and one of the most popular targeting factors in drug delivery systems.

In order to overcome the problems of low bioavailability and lack of targeting of inotodiol, in this study, we synthesized IOP-Lps and folic acid based targeting liposome FA-IOP-Lps[30], their cytotoxicity to cancer cells and normal were assessed via in vitro experiments, confirming that FA-IOP-Lps has significant anti-cancer activity and has minimal damage to normal stem cells.

\section{Materials And Methods}

\section{Materials}

Inonotus obliquus was purchased from the Northeast Natural Products Trading Company (Harbin, China). Ultrapure water was obtained from Millipore DQ-8 Ultrapure water system at SPST Public Platform and was used throughout all experiments. Tween 80 and cholesterol (Chol) are bought from Shanghai Aladin Chemical (Shanghai, China). 1,2-dialmitoyl-sn-glycero-3-phosphocholine (DPPC) is bought from Corden Pharma (Switzerland). 1,2-distearoyl-sn-glycero-3-phosphoethanolamine-N-[methoxy(poly(ethylene glycol))-2000] (DSPE-PEG 2000 ) and 1,2-distearoyl-sn-glycero-3-phosphoethanolamine-N-[folate (poly(ethylene glycol))-2000] (FA-DSPE-PEG 2000 ) are purchased from Shanghai Yare Biotech (Shanghai, China). 3-(4,5-dimethylthiazol-2-yl)-2,5-diphenyltetrazolium bromide (MTT), Dimethyl sulfoxide (DMSO, $\geq 99 \%$ ) and phosphate buffered saline (PBS) are all purchased from Solarbio Science \& Technology Co., Ltd (Beijing, China). 
L02 (normal human hepatic cells) were obtained from Chinese Academy of Sciences Committee on Type Culture Collection Cell Bank (Shanghai, China). HepG2 (human liver cancer cells), HeLa (human cervical cancer cells) and MCF-7 (human breast cancer cells) were previously purchased from Procell Life Science \& Technology Co., Ltd. (Shanghai, China) and were frozen in liquid nitrogen tanks in laboratory. Fetal bovine serum (FBS), penicillin-streptomycin solution and Dulbecco's modified Eagle's medium (DMEM, high glucose) were purchased from Gibco Life Technology (Gibco, USA). 96-well plate, pipet and cell culture bottle were bought from Corning (NY, USA). MTT, DMSO are cell culture grade, other reagents were at least of analytical grade and were used without further purification.

The chemical structure of DPPC (A), cholesterol (B), DSPE-PEG 2000 (C) and inotodiol (D) as Fig. 1.

Simulated gastric fluid (SGF) was prepared as Dr. Gao' s method [31]: $23.4 \mathrm{~mL} 38 \%$ concentrated hydrochloric acid and added $100 \mathrm{~mL}$ distilled water to prepare diluted hydrochloric acid, $1.64 \mathrm{~mL}$ dilute hydrochloric acid and $1 \mathrm{~g}$ of pepsin was added to $80 \mathrm{~mL}$ distilled water, then diluted to $100 \mathrm{~mL}$ with distilled water after they were mixed well.

\section{Isolation of inotodiol}

According to Lishuai Ma' s extraction method [32]: $2.0 \mathrm{~kg}$ sclerotia of Inonotus obliquus was ground to a fine power, followed by extraction with $60 \mathrm{~L} 80 \%$ ethanol for $2 \mathrm{~h}$ at $78^{\circ} \mathrm{C}$ for thrice and the ethanol extracts were then mixed, evaporation solvent using rotavapor, the resulting fractions were dried in vacuum, then extracted with petroleum ether (PE), followed by ethyl acetate (EA) extracted. The yield of petroleum ether fraction (PEF) is $38 \mathrm{~g}$.

For faster separation, the gradient was optimized on the basis of Ma' s[32]: $25 \mathrm{~g}$ PEF (5 g) was subjected to normal phase silica gel column chromatography and gradient elution $[750 \mathrm{~g}$, P.E. - EtOAc $(80: 20 \rightarrow$ 70:30 $\rightarrow$ 65:35 $\rightarrow$ 60:40 $\rightarrow 55: 45 \rightarrow 50: 40 \rightarrow$ 40:60)] to give 9 fractions (Fr.1 Fr.9). The fraction 4 was eluted by P.E. -EtOAc 60:40, after recrystallization using $\mathrm{MeOH}$ to give white acicular crystal compound, it was later identified by comparison of their spectral with reported values of TLC and $1 \mathrm{H}-\mathrm{NMR}$ to be inotodiol and the purity is over $98 \% .[\delta 0.75,0.82,0.88,0.99,1.01,1.67,1.77(3 \mathrm{H}, \mathrm{s}, \mathrm{H} 3-18,29,30,19,28$, 26, 27), $\delta 0.95(3 \mathrm{H}, \mathrm{d}, \mathrm{J}=6.6 \mathrm{~Hz}, \mathrm{H} 3-21), \delta 3.24(1 \mathrm{H}, \mathrm{dd}, \mathrm{J}=11.3,4.6 \mathrm{~Hz}, \mathrm{H}-5), \delta 3.69(1 \mathrm{H}, \mathrm{m}, \mathrm{J}=6.3,3.3 \mathrm{~Hz}, \mathrm{H}-$ 22), $\delta 5.19(1 \mathrm{H}, \mathrm{t}, \mathrm{J}=7.2 \mathrm{~Hz}, \mathrm{H}-24)]$

\section{Preparation of IOP liposomes (IOP-Lps) and FA-IOP-Lps}

IOP-Lps was prepared on the basis of the previously reported traditional methods[33], the preparation steps are shown in Fig. 2.

Briefly, IOP (1 mg), DPPC (15.98 mg), cholesterol $(3.75 \mathrm{mg})$ and DSPE-PEG 2000 (0.9 mg) were dissolved in methanol[34], after sonication, the supernatant were transferred into a $100 \mathrm{~mL}$ round bottom flask by pipet, then $15 \mathrm{ml}$ chloroform was added, dealt with ultrasonic for $5 \mathrm{~min}$, evaporate all solvent by rotary evaporation under high vacuum for $12 \mathrm{~h}$, a thick blue film, that is the IOP liposomes[35]. Finally, $100 \mathrm{~mL}$ 
ultrapure water was added into the flask and sonicated for 5 min to obtain the aqueous dispersion and was kept in $4{ }^{\circ} \mathrm{C}$ refrigerator for further use.

Formulations of different materials is list as Table 1.

Table 1 Orthogonal test design: $L_{9} \otimes 3^{4} \llbracket$ of inotodiol liposomes

\begin{tabular}{|c|c|c|c|}
\hline \multirow[t]{2}{*}{ Factor } & \multicolumn{3}{|l|}{ Level } \\
\hline & 1 & 2 & 3 \\
\hline A Chol『mg $\rrbracket$ & 2.5 & 3.75 & 5 \\
\hline B DPPC $₫ \mathrm{mg} \rrbracket$ & 10.65 & 15.98 & 21.3 \\
\hline C DSPE-PEG $2000 \rrbracket \mathrm{mg} \rrbracket$ & 0.6 & 0.9 & 1.2 \\
\hline D IOP $\mathbb{m g} \rrbracket$ & 0.5 & 1 & 1.5 \\
\hline
\end{tabular}

FA-IOP-Lps was later prepared at the optimal formulation of IOP-Lps by adding of extra $1 \mathrm{mg}$ FA- DSPE$\mathrm{PEG}_{2000}$.

\section{Determination of entrapment efficiency (EE) and drug loading capacity (DL) of IOP-Lps}

The EE and DL of liposome samples was determined by ultra centrifugation methods[36] and analyzed by HPLC.

The newly prepared liposome was quickly hydrated by $10.00 \mathrm{~mL} 0.01 \mathrm{X}$ PBS then centrifuged at $12,000 \mathrm{~g}$ for $30 \mathrm{~min}$. Then the supernatant was analyzed by RP-HPLC (Agilent 1220, USA), the absorbance at 244 $\mathrm{nm}$ UV were recorded and peak area were calculated. The amount of free drug was determined by standard calibration curve of peak area. The standard calibration curve was obtained using different concentration of pure inotodiol[37].

Entrapment efficiency (EE) and drug loading capacity (DL) were calculated using the following formula[38]:

$E E(\%)=M_{\text {entrapped }} / M_{\text {total }} \times 100 \%(1)$

$\operatorname{DL}(\%)=M_{\text {entrapped }} / M_{\text {Lps }} \times 100 \%(2)$

where $M_{\text {entrapped }}$ is the IOP amount entrapped in liposomes, $M_{\text {total }}$ is the total IOP amount in the resulted preparation and $\mathrm{M}_{\mathrm{Lps}}$ is the amount of total IOP in the resulted preparation.

\section{In vitro release of of IOP -Lps}


$2 \mathrm{~mL}$ of IOP-Lps was suspended in a MW 3500 dialysis bag[39,40] (activated by boiling water for 15 minutes) and then immersed into beaker with either $50 \mathrm{~mL}$ simulated gastric fluid (SGF), pH 5.5 phosphorous buffer and pH 7.4 PBS, each with $0.5 \%(\mathrm{v} / \mathrm{v})$ Tween-80, and stirring at $37^{\circ} \mathrm{C}$ under 200 $\mathrm{rpm}[47]$, beakers were wrapped with tin foil to protect them from light.

\section{Characterization of of blank liposome, IOP-Lps and FA-IOP-Lps}

\section{IR spectra of blank liposome, IOP-Lps and FA-IOP-Lps}

The infrared (IR) spectra of inotodiol, blank liposome, IOP-Lps and FA-IOP-Lps were characterized by potassium bromide $(\mathrm{KBr})$ tableting method[41] using Bruker infra-red spectrophotometer (TENSOR 27, Germany). A tiny drop of hydrated IOP-Lps and was drop onto the surface of potassium bromide tablet, the transmittance within the wave number range of $4000-400 \mathrm{~cm}^{-1}$ was measure after drying by infrared drying oven.

\section{Morphology of IOP-Lps}

One drop of IOP-Lps was taken and dropped on the copper net by the method of phosphotungstic acid negative staining[42]. After natural drying, it was negative stained with $1 \%$ phosphotungstic acid for $2 \mathrm{~min}$. After drying, the morphology of samples was characterized with transmission electron microscopy (TEM, JEM-2100F, JEOL, Japan).

\section{Particle size and zeta potential of IOP-Lps and FA-IOP-Lps}

The average particle size and zeta potential of samples was detected by dynamic light scattering (DLS) method by Malvern Zetasizer (Nano ZS 90, Malvern Instruments, UK) at room temperature[35]. Samples were suspensions with concentration below $1 \mathrm{mg} / \mathrm{ml}$.

All procedures were carried out in triplicate.

\section{Culture of HepG2, L02, MCF-7 and HeLa cells}

The frozen HepG2, L02, MCF-7 and HeLa cells were taken out from the liquid nitrogen tank and resuscitated rapidly, they were cultured with the medium consist of $90 \%$ DMEM, $10 \%(\mathrm{v} / \mathrm{v})$ FBS plus an extra $1 \%(\mathrm{v} / \mathrm{v})$ penicillin/streptomycin under standard incubation condition $\left(37^{\circ} \mathrm{C}, 5 \% \mathrm{CO}_{2}\right)$. The cells were carried out to subculture for 3 times until the growth condition is stable.

\section{In Vitro Cytotoxicity of inotodiol, IOP-Lps and FA-IOP-Lps}

The cytotoxicity of cancer and normal cells were assessed using MTT assay. HepG2, L02, MCF-7 and HeLa cells $\left(1 \times 10^{4}\right.$ cells per well) were seeded in a 96-well plate and incubated overnight under standard incubation condition $\left(37^{\circ} \mathrm{C}, 5 \% \mathrm{CO}_{2}\right)$. Various concentrations of samples were added into each well to replace the original medium, followed by incubating for $12 \mathrm{~h}, 24 \mathrm{~h}, 36 \mathrm{~h}$ under standard incubation condition. Afterward, MTT solution $(5 \mathrm{mg} / \mathrm{mL}, 20 \mu \mathrm{L})$ was added into each well and further incubated for 
$4 \mathrm{~h}$. Finally, after the removal of old media and the generated formazan were dissolved with DMSO under mild shaking, the OD value at $490 \mathrm{~nm}(570 \mathrm{~nm}$ as reference) of each well were immediately measured by an enzyme-linked immunosorbent assay reader[43] to calculate the viability and $\mathrm{IC}_{50}$.

\section{Statistical analysis}

In this experiment, datum were tested three times unless otherwise stated. ANOVA (analysis of variance) were used for statistically significance. $I_{50}$ value were obtain from SPSS software. Data are expressed as mean \pm standard deviation (SD).

\section{Results And Discussion}

\section{Encapsulation efficiency (EE) and drug-loading capacity (DL) of IOP-Lps}

It could be seen from Table 2 that under the selected factors and level conditions, the optimal combination condition was a3d2b1c3, and the influence degree of each factor on the encapsulation rate was $A \otimes D \otimes B \otimes C$, i.e. $5.00 \mathrm{mg}$ cholesterol, $10.65 \mathrm{mg} \mathrm{DPPC,} 1.20 \mathrm{mg} \mathrm{DSPE-PEG}{ }_{2000}, 1.00 \mathrm{mg}$ IOP. The highest encapsulation efficiency of liposomes was $77.33 \%$.

As shown in Table 2, the EE of IOP-Lps with different content was obtained. Overall, the EE of the nanocarriers mostly affected by cholesterol content. The EE gradually grows large as cholesterol content increased from $2.50 \mathrm{mg}$ to $5.00 \mathrm{mg}$, However, as cholesterol took up too much bilayer space, it will lead to membranes' rigidity gradually increased with fluidity decreased, besides, adding cholesterol may reduce the ratio of phospholipids used to form liposomes at the same time, which might lead to the leaking of content drug, this indicating that only certain amount of cholesterol could enhance the phospholipids in bilayer[35].

The EE and DL of IOP were $77.33 \%$ and $35.55 \%$, respectively.

Table 2 Orthogonal test results of IOP-Lps 


\begin{tabular}{|c|c|c|c|c|c|}
\hline \multirow[t]{2}{*}{ No. } & \multicolumn{4}{|l|}{ Factor } & \multirow[t]{2}{*}{$\mathrm{EE} \%$} \\
\hline & $\begin{array}{l}\text { A. Chol } \\
\text { 『mg } \rrbracket\end{array}$ & $\begin{array}{l}\text { B. DPPC } \\
\text { \mg } \mathbb{}\end{array}$ & $\begin{array}{l}\text { C. DSPE-PEG } 2000 \\
\rrbracket \mathrm{mg} \rrbracket\end{array}$ & $\begin{array}{l}\text { D. IOP } \\
\text { 『mg }\end{array}$ & \\
\hline 1 & 2.50 & 10.65 & 0.60 & 0.50 & 61.24 \\
\hline 2 & 2.50 & 15.98 & 0.90 & 1.00 & 61.77 \\
\hline 3 & 2.50 & 21.30 & 1.20 & 1.50 & 56.83 \\
\hline 4 & 3.75 & 10.65 & 0.90 & 1.50 & 65.34 \\
\hline 5 & 3.75 & 15.98 & 1.20 & 0.50 & 62.58 \\
\hline 6 & 3.75 & 21.30 & 0.60 & 1.00 & 72.16 \\
\hline 7 & 5.00 & 10.65 & 1.20 & 1.00 & 77.33 \\
\hline 8 & 5.00 & 15.98 & 0.60 & 1.50 & 71.04 \\
\hline 9 & 5.00 & 21.30 & 0.90 & 0.50 & 70.53 \\
\hline K1 & 59.95 & 67.97 & 68.15 & 64.78 & \\
\hline K2 & 66.69 & 65.13 & 65.88 & 70.42 & \\
\hline K3 & 72.97 & 66.51 & 65.58 & 64.40 & \\
\hline $\mathrm{R}$ & 13.02 & 2.84 & 2.57 & 6.02 & \\
\hline Factor Preference & $A D B C$ & & & & \\
\hline $\begin{array}{l}\text { Optimization } \\
\text { scheme }\end{array}$ & $A_{3} D_{2} B_{1} C_{3}$ & & & & \\
\hline
\end{tabular}

\section{Particle size, zeta potential and morphology of IOP-Lps and FA-IOP-Lps}

The particle size of the sixth group with the highest encapsulation efficiency was measured. As shown in Fig. $3 \mathrm{a}$ and $3 \mathrm{~b}$, the Z-average of IOP-Lps was $254.7 \mathrm{~nm}$ and the zeta potential was - $50.2 \mathrm{mV}$ before passing through the membrane. After sonication and filtered with $0.22 \mu \mathrm{m}$ needle filter, the Z-average decreased to $201.07 \pm 6.47 \mathrm{~nm}$ and the zeta potential was $-59.8 \pm 7.3 \mathrm{mV}$. The Z-average of FA-IOP-Lps was $224.33 \pm 1.86 \mathrm{~nm}$ and zeta potential was $-54.6 \pm 5.7 \mathrm{mV}$ (measured after sonication and filtered with $0.22 \mu \mathrm{m}$ needle filter). The hydrated liposomes were easy to agglomerate, to a certain extent the ultrasonic treatment inhibited the aggregation, the decrease in Z-average also attributed to the elimination of particles whose size exceeds $220 \mathrm{~nm}$, so that the average value is reduced. According to Hadian, the liposome of $<-30 \mathrm{mV}$ zeta potential are considered as optimum formulation, showing that the obtained liposome is relatively stable. Besides, the polydispersity index (PDI) was $0.388 \pm 0.017$ in 0.01 x PBS indicate relative low variance, and liposomes were well dispersed $[44,45]$. 
Transmission electron microscopy (TEM) was used to showed its morphology. It can be seen from the Fig. 3c, 3d, 3e that the IOP-Lps are irregular or nearly spherical, well dispersed, but slightly agglomerated. These results confirmed that IOP were successfully coated into phospholipid.

It is worth noting that the liposome particle size seen under TEM was about $100 \mathrm{~nm}$, which was significantly smaller than the data measured by DLS, this experiment was done in triplicate and of different concentration to avoid the influence of concentration, this phenomena might be attributed to PEGylation[33,46], PEG was not successfully dyed by phosphotungstic acid, therefore it could not be observed under TEM.

\section{Infrared characterization}

As Fig. $3 \mathrm{f}$ has shown, the characteristic absorption peak of blank liposome, $2930 \mathrm{~cm}^{-1}$ was the saturated $\mathrm{C}-\mathrm{H}$ stretching vibration absorption peak, $2850 \mathrm{~cm}^{-1}$ was the $\mathrm{CH}_{2}$ symmetric stretching absorption peak, $1740 \mathrm{~cm}^{-1}$ was the stretching vibration of $\mathrm{C}=0$ in phospholipid, the contrast showed that due to the influence of $1630 \mathrm{~cm}^{-1}$, the absorption of $\mathrm{C}=0$ in $1740 \mathrm{~cm}^{-1}$ became stronger, and the absorption frequency of $\mathrm{C}=\mathrm{O}$ in the two substances increases with the overlap of $\mathrm{C}=\mathrm{O}$ absorption peak, and there was an absorption peak at $1360 \mathrm{~cm}^{-1}$, but there was no such absorption peak in the blank liposome. It was speculated to be the result of the angular vibration $\left(1410 \mathrm{~cm}^{-1}\right)$ of $-\mathrm{CH}_{2}$ - in IOP moving to lower wavenumbers. Therefore, IOP was successfully incorporated into the liposome $[47,48]$.

\section{In vitro release}

The dialysis method was used in the experiment to detect the release of IOP in SGF, pH 5.5 PBS and 0.01x pH 7.4 PBS. As shown in Fig. 3g, the free IOP release rates in SGF, pH 5.5 PBS and pH 7.4 PBS were 89.51 $\pm 0.56 \%, 84.59 \pm 0.53 \%$ and $83.18 \pm 0.47 \%$ respectively, and IOP-Lps release rates in SGF, pH 5.5 PBS and $\mathrm{pH} 7.4$ PBS were $57.02 \pm 0.43 \%, 49.57 \pm 0.63 \%$ and $50.98 \pm 0.62 \%$ respectively. The release speed was relatively large at the initial $24 \mathrm{~h}$, and subsequently slowed down, as reported in previous studies. A large burst in the initial phase was mainly due to the separation of the drug from the outer surface of the lipid; the subsequent slow release was mainly due to the diffusion of the drug across the liposome bilayer into the release medium[49]. Therefore, liposomes can effectively slow down the release of drug.

\section{Cellular cytotoxicity assay}

To evaluate the cytotoxicity of different concentrations of IOP-Lps to cancer and normal cells, MTT assays were carried out to determine cell viabilities.

Hela, HepG2, MCF-7 and normal Hepatic L02 cells were treated with full culture medium as negative control, IOP as positive control, IOP-Lps as control group of different concentration.

The HepG2 cell viability as list in Fig. 4. 
From Fig. 4 the cell viability revealed that the FA-IOP-Lps had the best inhibition rate of HepG2 cells. And the living cells under microscope in Fig. 5 also confirmed that liposome significantly promote IOP' $\mathrm{s}$ inhibition of HepG2 cells.

The $\mathrm{IC}_{50}$ values of IOP, IOP-Lps and FA-IOP-Lps are shown in Table 3a,b,c.

Table $3 a \mathrm{IC}_{50}$ values of HepG2 cells treated with IOP, IOP-Lps and FA-IOP-Lps

\begin{tabular}{|llll|}
\hline Drug & $12 \mathrm{~h} \mathrm{IC}_{50}$ & $24 \mathrm{~h} \mathrm{IC}_{50}$ & $48 \mathrm{~h} \mathrm{IC}$ \\
\hline IOP & $108.42 \pm 0.92$ & $97.53 \pm 0.76$ & $89.83 \pm 0.79$ \\
\hline IOP-Lps & $113.08 \pm 0.46$ & $100.04 \pm 0.55$ & $82.09 \pm 0.46$ \\
\hline FA-IOP-Lps & $104.53 \pm 0.53$ & $93.28 \pm 0.84$ & $74.56 \pm 0.37$ \\
\hline
\end{tabular}

Table $3 \mathbf{b}$ IC $\mathrm{C}_{50}$ values of L02 cells treated with IOP, IOP-Lps and FA-IOP-Lps

\begin{tabular}{|llll|}
\hline Drug & $12 \mathrm{~h} \mathrm{IC}_{50}$ & $24 \mathrm{~h} \mathrm{IC}_{50}$ & $48 \mathrm{~h} \mathrm{IC}_{50}$ \\
\hline IOP & $1011.24 \pm 6.14$ & $759.62 \pm 4.51$ & $637.96 \pm 5.09$ \\
\hline IOP-Lps & $1298.43 \pm 7.19$ & $1054.96 \pm 7.05$ & $937.92 \pm 5.26$ \\
\hline FA-IOP-Lps & $1322.49 \pm 5.23$ & $1092.39 \pm 5.04$ & $967.45 \pm 6.07$ \\
\hline
\end{tabular}

Table $3 \mathrm{CIC}_{50}$ values of MCF-7 cells treated with IOP, IOP-Lps and FA-IOP-Lps

\begin{tabular}{|llll|}
\hline Drug & $12 \mathrm{~h} \mathrm{IC}_{50}$ & $24 \mathrm{~h} \mathrm{IC}$ & $48 \mathrm{~h} \mathrm{IC}$ \\
\hline IOP & $201.24 \pm 1.96$ & $166.13 \pm 2.02$ & $143.79 \pm 1.49$ \\
\hline IOP-Lps & $165.28 \pm 1.75$ & $158.25 \pm 1.53$ & $156.35 \pm 1.35$ \\
\hline FA-IOP-Lps & $149.53 \pm 1.97$ & $150.04 \pm 1.69$ & $147.62 \pm 1.74$ \\
\hline
\end{tabular}

It can be seen from the above results that the $\mathrm{IC}_{50}$ value of $\mathrm{L} 02$ cells were significantly larger than HepG2 cells and indicate IOP-Lps and FA-IOP-Lps tend to kill cancer cells while harming few normal healthy cells, especially FA-IOP-Lps, with highest IC $\mathrm{C}_{50}$ value for normal cells and lowest $I \mathrm{C}_{50}$ value for cancer cells among three types of agents. For MCF-7 cells, FA-IOP-Lps also showing favorable antitcancer effect.

Liposomes have the same phospholipid bilayer structure as cell membranes[50]. This structural feature promotes the ability of cells uptake of IOP in liposomes. At the same time, folate receptor (FR) 
overexpression[29] in cancer cells, it works along with enhanced permeability and retention effect (EPR) to promotes FA-IOP-Lps to recognize and accurately target cancer cells.

\section{Conclusions}

In this study, the inotodiol liposomes IOP-Lps and FA-IOP-Lps possessing significant anticancer properties were prepared, the synthesized optimum FA-IOP-Lps were of considerable particle size ( $Z$ average 224.33 $\mathrm{nm}$ ), good stability (zeta potential $-54.6 \mathrm{mV}$ ), uniform spherical morphology, good entrapment efficiency (77.25\%) and mono disperse condition (PDI) which are highly recommended for the effective in vitro and in vivo drug release. With the $48 \mathrm{~h} \mathrm{IC}_{50}$ value of 82.09 and $74.56 \mu \mathrm{mol} / \mathrm{mL}$ for HepG2 (liver hepatocellular cells), respectively, confirming that coating FA modified PEG, liposomes could control the release of IOP and enabled active target delivery to treat cancer cells and enhance intracellular uptake, while it shows very low toxicity to L02 normal healthy cells. It is a controllable programed of targeted chemotherapy. The in vitro experiment results exhibited its excellent anticancer efficiency and be a powerful targeted chemotherapy for destruction of cancers. This is the first in vitro study for inotodiol liposome and provide scientific information for further study for the application of intodiol. The significance of this study is that these findings demonstrated FA-IOP-Lps significantly increased bioavailability of inotodiol, we hope this study will contribute to further research in vivo, and help those patients who are suffering from cancers.

\section{Declarations}

Ethics approval and consent to participate Not applicable

Consent for publication Not applicable

Availability of data and materials Both the materials and the datas generated and analyzed during the present study are available from the corresponding author on reasonable request.

Competing interests There are no conflicts to declare.

Funding This work was supported by the grant from the Tianjin Municipal Science and Technology Foundation (Grant No. 18PTZWHZ00190) and National Natural Science Foundation of China (Grant No. 31371879).

Authors' contributions Yangpeng Lu contributed to the design of experiments, methodology, verification, software, formal analysis, in vitro release studies, data analysis and write manuscript. Xudong Gao and Zhongqin Chen contributed to the cell culture and cytotoxicity assay, Zihan Xue, Yanan Jia Nannan Li and Yajie Wang contributed substantially to data acquisition, statistical analysis, and data interpretation. Haxia Chen has made an vital contribution to the supervision of the manuscript and funding the experiment. All authors read and approved the final manuscript. 
Acknowledgements Great thanks to Dr. Xinghua Jin, Mr. Zhi Li and Ms. Shuyu Yang, IAC of SPST, TJU, and Ms. Xiaojuan Deng of IAC, TJU, for their kindly help and assistance in instrumental analysis.

\section{References}

1. Sciacovelli M, Schmidt C, Maher ER, Frezza C (2020) Metabolic Drivers in Hereditary Cancer Syndromes. Annu Rev Canc Biol 4:77-97. doi:10.1146/annurev-cancerbio-030419-033612

2. Subotic S, Wyler S, Bachmann A (2012) Surgical Treatment of Localised Renal Cancer. Eur Urol Suppl 11 (3):60-65. doi:10.1016/j.eursup.2012.04.002

3. Rossi P, De La Torre ER, Mitsikostas D, Di Lorenzo C, Palmaro A (2020) Availability of Effective Evidence-Based Symptomatic Treatments for Cluster Headache in the EU Countries-A Survey of the European Headache Alliance and European Headache Federation. J Oral Facial Pain H 34 (1):7-12

4. Contursi A, Grande R, Dovizio M, Bruno A, Fullone R, Patrignani P (2018) Platelets in cancer development and diagnosis. Biochem Soc T 46:1517-1527

5. Wang H, Mou SY, Tu M (2020) Study on the Effect of Nano Albumin Paclitaxel Combined with Carboplatin in the Treatment of Lung Squamous Cell Carcinoma. J Nanosci Nanotechno 20 (12):7439-7443

6. Heavey S, O'Byrne KJ, Gately K (2014) Strategies for co-targeting the PI3K/AKT/mTOR pathway in NSCLC. Cancer Treat Rev 40 (3):445-456. doi:10.1016/j.ctrv.2013.08.006

7. Al Sawaftah NM, Husseini GA (2020) Ultrasound-Mediated Drug Delivery in Cancer Therapy: A Review. J Nanosci Nanotechno 20 (12):7211-7230

8. Nguyen TMN, Le HS, Le BV, Kim YH, Hwang I (2020) Anti-allergic effect of inotodiol, a lanostane triterpenoid from Chaga mushroom, via selective inhibition of mast cell function. Int Immunopharmacol 81. doi:ARTN 106244 10.1016/j.intimp.2020.106244

9. Baek J, Roh HS, Baek KH, Lee S, Lee S, Song SS, Kim KH (2018) Bioactivity-based analysis and chemical characterization of cytotoxic constituents from Chaga mushroom (Inonotus obliquus) that induce apoptosis in human lung adenocarcinoma cells. J Ethnopharmacol 224:63-75. doi:10.1016/j.jep.2018.05.025

10. Chung MJ, Chung CK, Jeong Y, Ham SS (2010) Anticancer activity of subfractions containing pure compounds of Chaga mushroom (Inonotus obliquus) extract in human cancer cells and in Balbc/c mice bearing Sarcoma-180 cells. Nutr Res Pract 4 (3):177-182. doi:10.4162/nrp.2010.4.3.177

11. Zhao FQ, Mai QQ, Ma JH, Xu M, Wang X, Cui TT, Qiu F, Han G (2015) Triterpenoids from Inonotus obliquus and their antitumor activities. Fitoterapia 101:34-40. doi:10.1016/j.fitote.2014.12.005

12. Radzhesh KT, Reshetova IG, Kamernitskii AV (1991) New Synthesis of (22r)-Lanosta-8,24-Diene-3Beta,22-Diol (Inotodiol) and Lanosterine 23-Keto Derivatives. B Acad Sci Ussr Ch+ 40 (11):2317-2318. doi:Doi 10.1007/Bf00961063

13. Cevc G, Richardsen H (1999) Lipid vesicles and membrane fusion. Adv Drug Deliver Rev 38 (3):207232. doi:Doi 10.1016/S0169-409x(99)00030-7 
14. Torchilin VP (2006) Multifunctional nanocarriers. Adv Drug Deliver Rev 58 (14):1532-1555. doi:10.1016/j.addr.2006.09.009

15. Danhier F (2016) To exploit the tumor microenvironment: Since the EPR effect fails in the clinic, what is the future of nanomedicine? J Control Release 244:108-121

16. Duncan R, Sat YN (1998) Tumour targeting by enhanced permeability and retention (EPR) effect. Ann Oncol 9:39-39

17. Maeda $\mathrm{H}$ (2012) Macromolecular therapeutics in cancer treatment: The EPR effect and beyond. J Control Release 164 (2):138-144. doi:10.1016/j.jconrel.2012.04.038

18. Lozano E, Asensio M, Perez-Silva L, Banales JM, Briz O, Marin JJG (2020) MRP3-Mediated Chemoresistance in Cholangiocarcinoma: Target for Chemosensitization Through Restoring SOX17 Expression. Hepatology. doi:10.1002/hep.31088

19. Nichols JW, Bae YH (2014) EPR: Evidence and fallacy. J Control Release 190:451-464

20. Song C, Shen MW, Rodrigues J, Mignani S, Majoral JP, Shi XY (2020) Superstructured poly(amidoamine) dendrimer-based nanoconstructs as platforms for cancer nanomedicine: A concise review. Coordin Chem Rev 421

21. Yang CL, Fu YY, Huang C, Hu DR, Zhou K, Hao Y, Chu BY, Yang Y, Qian ZY (2020) Chlorin e6 and CRISPR-Cas9 dual-loading system with deep penetration for a synergistic tumoral photodynamicimmunotherapy. Biomaterials 255

22. Ray S, Murkin AS (2019) New Electrophiles and Strategies for Mechanism-Based and Targeted Covalent Inhibitor Design. Biochemistry-Us 58 (52):5234-5244

23. Abe K, Yamamoto N, Domoto T, Bolidong D, Hayashi K, Takeuchi A, Miwa S, Igarashi K, Inatani H, Aoki Y, Higuchi T, Taniguchi Y, Yonezawa H, Araki Y, Aiba H, Minamoto T, Tsuchiya H (2020) Glycogen synthase kinase 3 beta as a potential therapeutic target in synovial sarcoma and fibrosarcoma. Cancer Sci 111 (2):429-440

24. Bailey SW, Ayling JE (2009) The extremely slow and variable activity of dihydrofolate reductase in human liver and its implications for high folic acid intake. P Natl Acad Sci USA 106 (36):1542415429. doi:10.1073/pnas.0902072106

25. Mansur AAP, Mansur HS, Leonel AG, Carvalho IC, Lage MCG, Carvalho SM, Krambrock K, Lobato ZIP (2020) Supramolecular magnetonanohybrids for multimodal targeted therapy of triple-negative breast cancer cells. J Mater Chem B 8 (32):7166-7188. doi:10.1039/d0tb01175d

26. Rangasamy L, Chelvam V, Kanduluru AK, Srinivasarao M, Bandara NA, You F, Orellana EA, Kasinski AL, Low PS (2018) New Mechanism for Release of Endosomal Contents: Osmotic Lysis via NigericinMediated K+/H+ Exchange. Bioconjugate Chem 29 (4):1047-1059

27. Suen WLL, Chau Y (2014) Size- dependent internalisation of folate- decorated nanoparticles via the pathways of clathrin and caveolae- mediated endocytosis in ARPE-19 cells. J Pharm Pharmacol 66 (4):564-573

28. Andrade KN, Knauth P, Lopez Z, Hirata GA, Martinez SJG, Arizaga GGC (2020) Assembly of folatecarbon dots in GdDy-doped layered double hydroxides for targeted delivery of doxorubicin. Appl Clay 


\section{Sci 192}

29. Pierce JT, Cho SS, Nag S, Zeh R, Jeon J, Holt D, Durham A, Nasrallah MP, Singhal S, Lee JYK (2019) Folate Receptor Overexpression in Human and Canine Meningiomas-Immunohistochemistry and Case Report of Intraoperative Molecular Imaging. Neurosurgery 85 (3):359-368

30. Yang SY, Zhu WS, Wang ZW, Xiao YM, Mao P, Qu LB, Hu YS, Wang JS (2020) Thermosensitive Liposomes Encapsulating Anti-Cancer Agent Lomustine, and Contrast Medium lohexol, for Thermochemotherapy: Preparation, Characterization, and In Vivo Evaluation. J Nanosci Nanotechno 20 (10):6070-6076. doi:10.1166/jnn.2020.18590

31. Gao X, Santhanam RK, Xue Z, Jia Y, Wang Y, Lu Y, Phisalaphong M, Chen H (2020) Antioxidant, alpha-amylase and alpha-glucosidase activity of various solvent fractions of I. obliquus and the preventive role of active fraction against $\mathrm{H} 2 \mathrm{O} 2$ induced damage in hepatic $\mathrm{LO} 2$ cells as fungisome. J Food Sci 85 (4):1060-1069. doi:10.1111/1750-3841.15084

32. Ma L, Chen H, Dong P, Lu X (2013) Anti-inflammatory and anticancer activities of extracts and compounds from the mushroom Inonotus obliquus. Food Chem 139 (1-4):503-508. doi:10.1016/j.foodchem.2013.01.030

33. Sun Q, You Q, Wang J, Liu L, Wang Y, Song Y, Cheng Y, Wang S, Tan F, Li N (2018) Theranostic Nanoplatform: Triple-Modal Imaging-Guided Synergistic Cancer Therapy Based on LiposomeConjugated Mesoporous Silica Nanoparticles. ACS Appl Mater Interfaces 10 (2):1963-1975. doi:10.1021/acsami.7b13651

34. Zhang WL, Wang ZY, Wu CC, Jin Y, Liu XY, Wu ZM, Liu JP (2018) The effect of DSPE-PEG(2000), cholesterol and drug incorporated in bilayer on the formation of discoidal micelles. European Journal of Pharmaceutical Sciences 125:74-85

35. Sun Q, You Q, Wang JP, Liu L, Wang YD, Song YL, Cheng Y, Wang SY, Tan FP, Li N (2018) Theranostic Nanoplatform: Triple-Modal Imaging-Guided Synergistic Cancer Therapy Based on LiposomeConjugated Mesoporous Silica Nanoparticles. Acs Appl Mater Inter 10 (2):1963-1975. doi:10.1021/acsami.7b13651

36. Richter AR, Feitosa JPA, Paula HCB, Goycoolea FM, de Paula RCM (2018) Pickering emulsion stabilized by cashew gum- poly-L-lactide copolymer nanoparticles: Synthesis, characterization and amphotericin B encapsulation. Colloid Surface B 164:201-209

37. Xu F, Gong BL, Xu ZX, Wang JJ (2020) Reverse-phase/phenylboronic-acid-type magnetic microspheres to eliminate the matrix effects in amatoxin and phallotoxin determination via ultrahighperformance liquid chromatography-tandem mass spectrometry. Food Chemistry 332

38. Wu H, Luo Y, Xu D, Ke X, Ci T (2020) Low molecular weight heparin modified bone targeting liposomes for orthotopic osteosarcoma and breast cancer bone metastatic tumors. Int J Biol Macromol. doi:10.1016/j.jibiomac.2020.08.068

39. Ruiz A, Ma G, Seitsonen J, Pereira S, Ruokolainen J, Al-Jamal WT (2020) Encapsulated doxorubicin crystals influence lysolipid temperature-sensitive liposomes release and therapeutic efficacy in vitro and in vivo. J Control Release. doi:10.1016/j.jconrel.2020.09.032 
40. Zhai B, Chen P, Wang W, Liu S, Feng J, Duan T, Xiang Y, Zhang R, Zhang M, Han X, Chen X, Li Q, Li G, Liu Y, Huang X, Zhang W, Pan T, Yan L, Jin T, Xie T, Sui X (2020) An ATF24 peptide-functionalized beta-elemene-nanostructured lipid carrier combined with cisplatin for bladder cancer treatment. Cancer Biol Med 17 (3):676-692. doi:10.20892/j.issn.2095-3941.2020.0454

41. Volmer M, de Vries JC, Goldschmidt HM (2001) Infrared analysis of urinary calculi by a single reflection accessory and a neural network interpretation algorithm. Clin Chem 47 (7):1287-1296

42. Asadi J, Ferguson S, Raja H, Hacker C, Marius P, Ward R, Pliotas C, Naismith J, Lucocq J (2017) Enhanced imaging of lipid rich nanoparticles embedded in methylcellulose films for transmission electron microscopy using mixtures of heavy metals. Micron 99:40-48. doi:10.1016/j.micron.2017.03.019

43. Talbaoui A, El Hamdaoui L, Bouyahya A, El Moussaouiti M, Bakri Y (2020) Chemical Composition, in vitro Cytotoxic, and Antibacterial Activities of Moroccan Medicinal Plants Euphorbia resinifera and Marrubium vulgare. Biointerface Res App 10 (6):7343-7355. doi:10.33263/Briac106.73437355

44. Greenwood R, Kendall K (1999) Selection of suitable dispersants for aqueous suspensions of zirconia and titania powders using acoustophoresis. J Eur Ceram Soc 19 (4):479-488

45. Hadian Z, Sahari MA, Moghimi HR, Barzegar M (2014) Formulation, Characterization and Optimization of Liposomes Containing Eicosapentaenoic and Docosahexaenoic Acids; A Methodology Approach. Iran J Pharm Res 13 (2):393-404

46. Najafipour A, Mahdavian AR, Aliabadi HS, Fassihi A (2020) Dual thermo- and pH-responsive poly(Nisopropylacrylamide-co-(2-dimethylamino) ethyl methacrylate)-g-PEG nanoparticle system and its potential in controlled drug release. Polym Bull 77 (6):3129-3142

47. Gao XD, Santhanam RK, Xue ZH, Jia YA, Wang YJ, Lu YP, Phisalaphong M, Chen HX (2020) Antioxidant, alpha-amylase and alpha-glucosidase activity of various solvent fractions of I. obliquus and the preventive role of active fraction against $\mathrm{H} 2 \mathrm{O} 2$ induced damage in hepatic L02 cells as fungisome. Journal of Food Science 85 (4):1060-1069

48. Xue J, Tong SS, Wang ZR, Liu P (2018) Chemical Characterization and Hypoglycaemic Activities In Vitro of Two Polysaccharides from Inonotus obliquus by Submerged Culture. Molecules 23 (12)

49. Panwar P, Pandey B, Lakhera PC, Singh KP (2010) Preparation, characterization, and in vitro release study of albendazole-encapsulated nanosize liposomes. Int J Nanomed 5:101-108

50. Zhang W, Wang Z, Wu C, Jin Y, Liu X, Wu Z, Liu J (2018) The effect of DSPE-PEG2000, cholesterol and drug incorporated in bilayer on the formation of discoidal micelles. Eur J Pharm Sci 125:74-85. doi:10.1016/j.ejps.2018.09.013

\section{Figures}




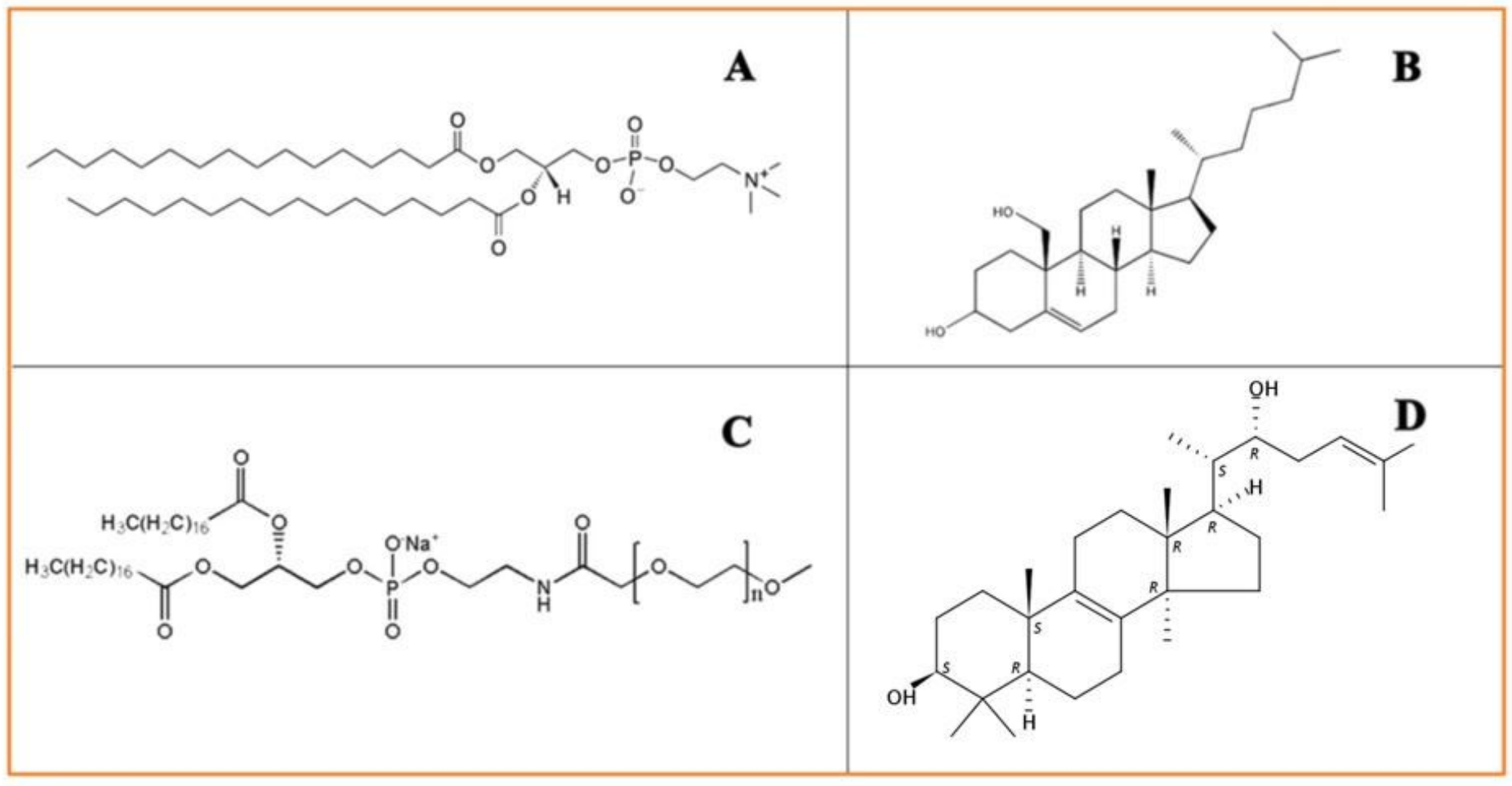

Figure 1

Chemical structures of DPPC (A), cholesterol (B), DSPE-PEG2000 (C) and inotodiol (D). 


\section{Inonotus Obliquus powder $+\mathrm{EtOH}$ \\ EtOAc Extract, \\ Column Chromatographic Separation, \\ - Recrystallization, \\ Inotodiol (IOP) \\ - Chloroform \\ IOP solution}

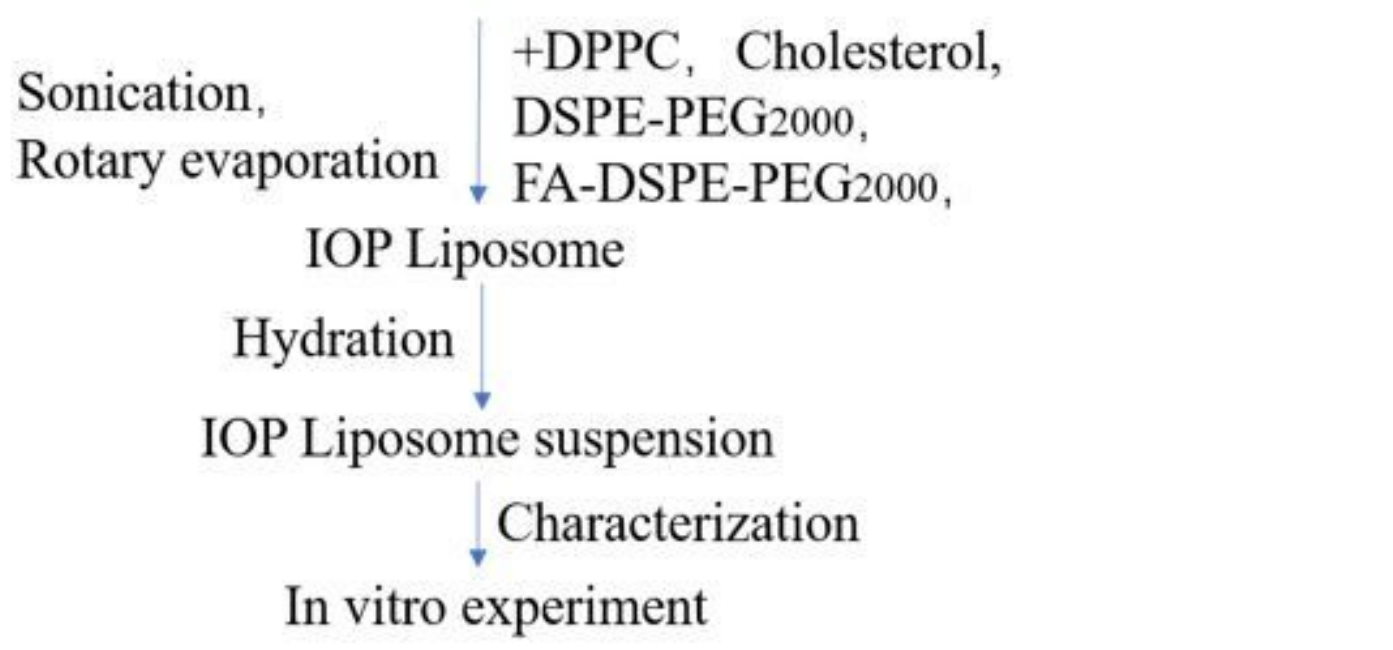

Figure 2

Preparation steps flow chart of IOP-Lps 
Results

\begin{tabular}{|c|c|c|c|c|c|c|c|c|c|c|}
\hline \multirow[b]{2}{*}{ Z-Average (d.nm): } & \multirow[b]{2}{*}{2547} & \multirow[b]{2}{*}{ Peak 1: } & \multirow{2}{*}{$\begin{array}{l}\text { Size (d.nm): } \\
362.3\end{array}$} & \multirow{2}{*}{$\begin{array}{l}\text { \% Volume: } \\
45.2\end{array}$} & \multirow{2}{*}{$\begin{array}{l}\text { St Dev (d.nm): } \\
136.7\end{array}$} & \multicolumn{2}{|l|}{ Results } & Mean $(m V)$ & Area (\%) & St Dev $(\mathrm{mV})$ \\
\hline & & & & & & Zeta Potential $(\mathrm{mV}):-50.2$ & Peak 1: & .50 .2 & 100.0 & 8.51 \\
\hline Pdt: & 0.392 & Peak 2: & 87.49 & 52.7 & 28.41 & Zeta Deviation $(\mathrm{mV}): 8.51$ & Peak 2: & 0.00 & 0.0 & 0.00 \\
\hline $\begin{array}{l}\text { Intercept: } \\
\text { Result quality }\end{array}$ & 0.974 & Peak 3: & 5465 & 2.1 & 634.0 & Conductivity (ms/cm): 0.0250 & Peak 3: & 0.00 & 0.0 & 0.00 \\
\hline & & & & & & Result quality See res & ity report & & & \\
\hline
\end{tabular}
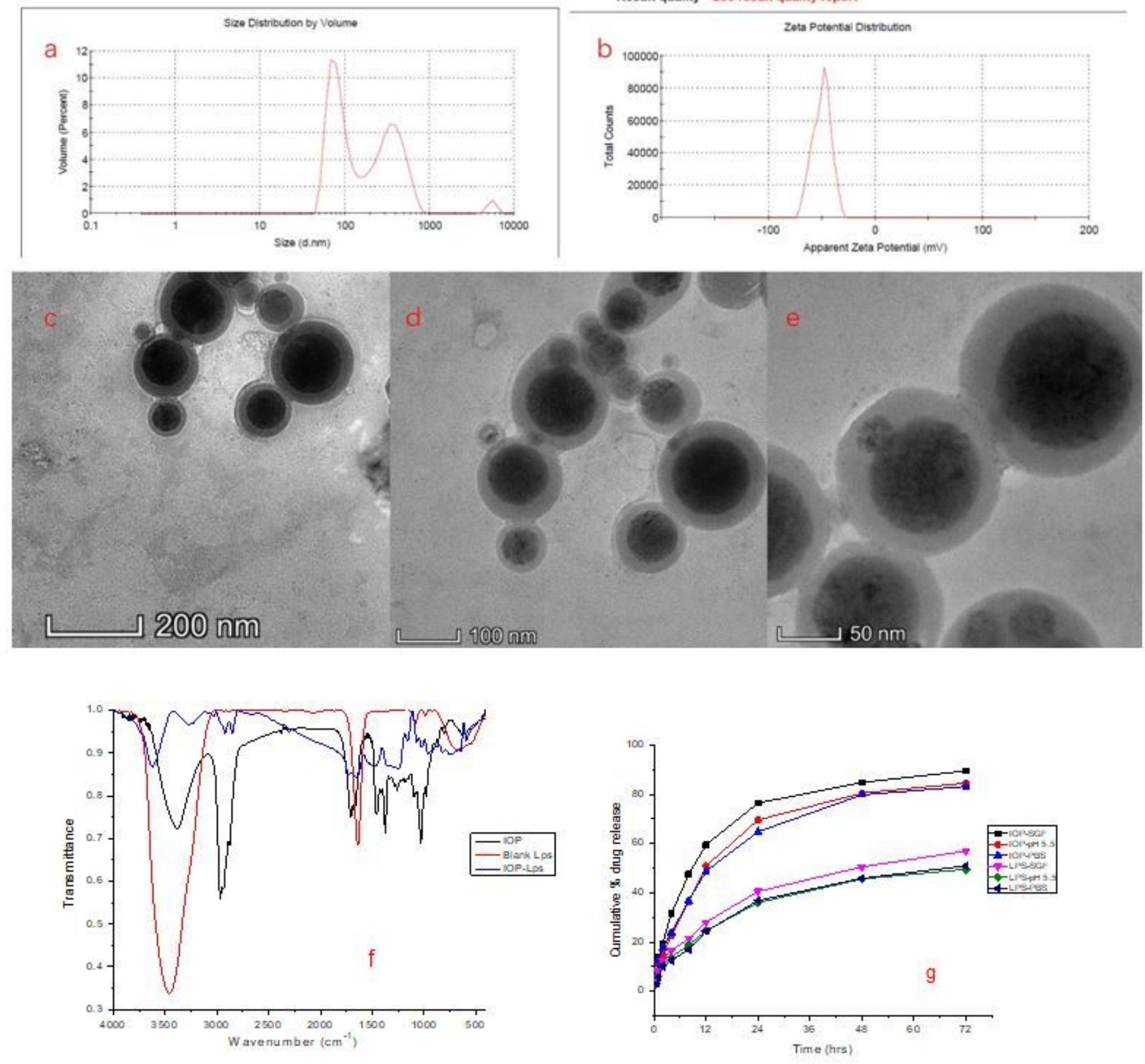

Figure 3

Characterization of IOP, IOP-Lps and blank Lps, particle size by DLS(a), zeta potential (b), TEM image of IOP-Lps $(c, d, e)$,Infrared spectrum(f), in vitro release(g) 


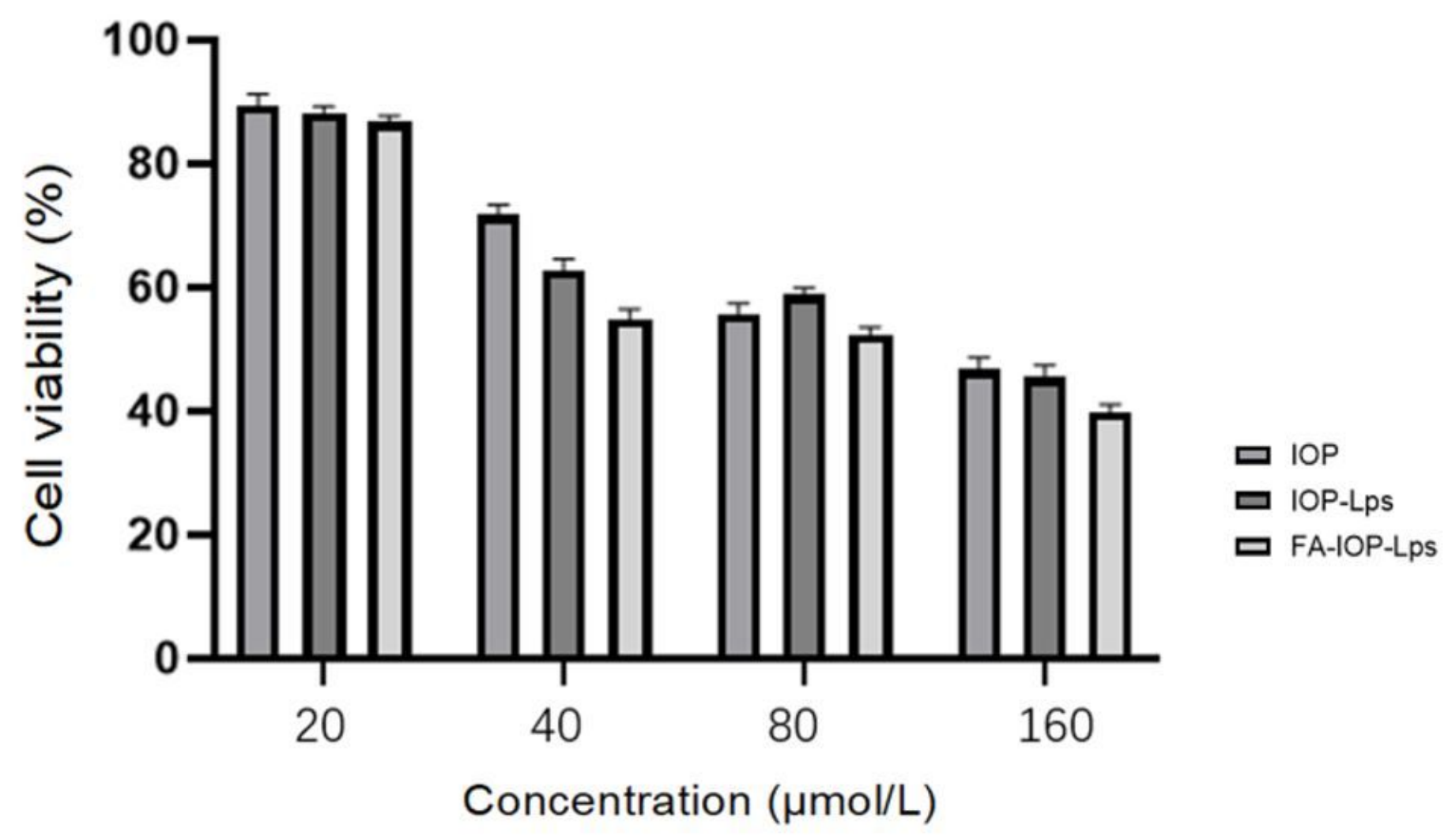

Figure 4

HepG2 cell viability after treated with IOP, IOP-Lps and FA-IOP-Lps for $48 \mathrm{~h}$ at concentration of $20 \mu \mathrm{mol} / \mathrm{L}$, $40 \mu \mathrm{mol} / \mathrm{L}, 80 \mu \mathrm{mol} / \mathrm{L}, 160 \mu \mathrm{mol} / \mathrm{L}$, respectively 

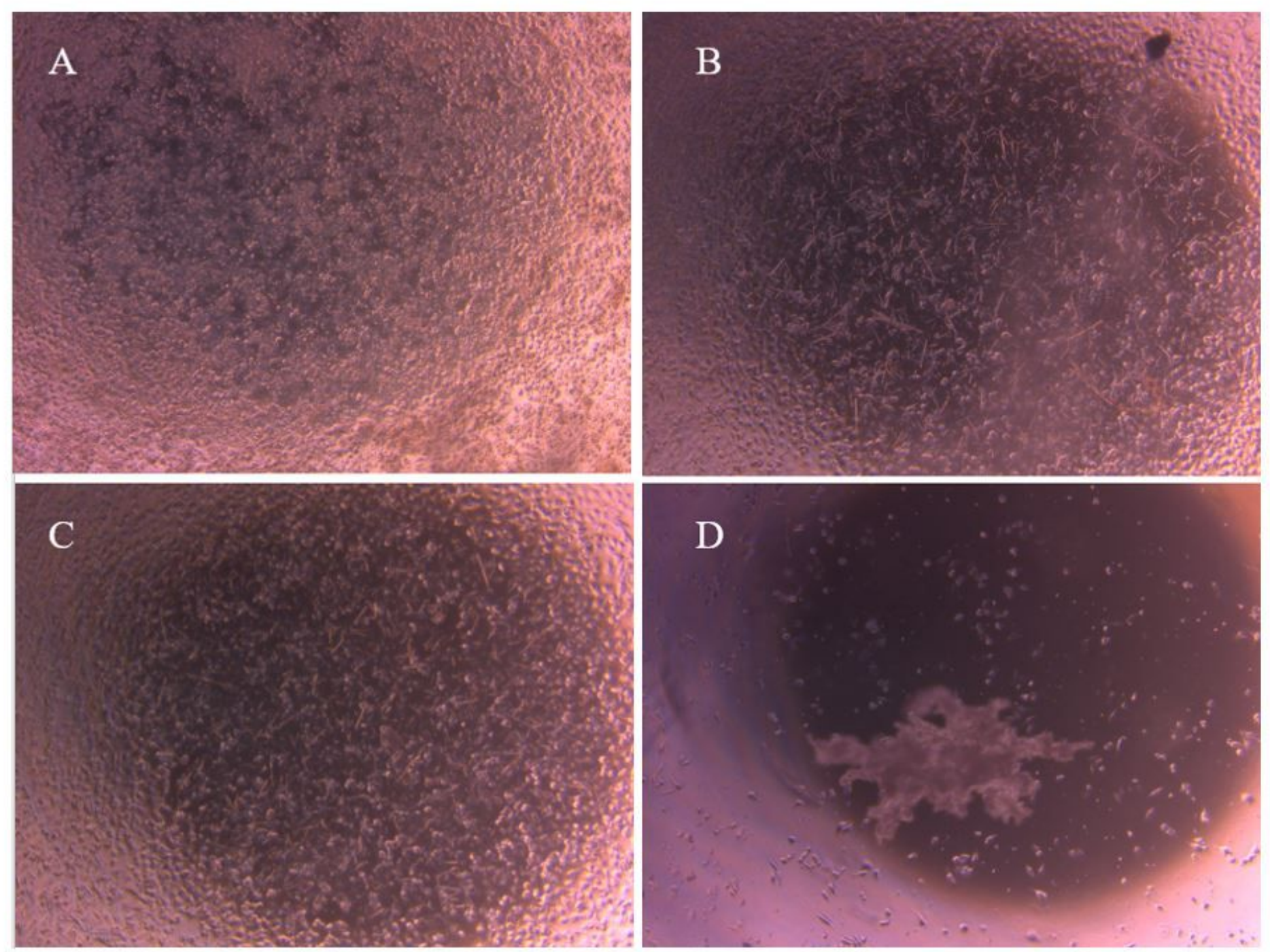

\section{Figure 5}

HepG2 Cell Negative Control(a), Positive Control (treated with IOP) (b), Treated with IOP-NPs(c), Treated with IOP-LPs (d) 